\title{
Efficacy of botulinum toxin in the management of temporomandibular myofascial pain and sleep bruxism
}

\author{
Hatice Hosgor, Sezen Altindis \\ Department of Oral and Maxillofacial Surgery, Faculty of Dentistry, Kocaeli University, Kocaeli, Turkey
}

\begin{abstract}
J Korean Assoc Oral Maxillofac Surg 2020;46:335-340)
Objectives: This study sought to evaluate the efficacy of injecting botulinum toxin into the masseter and temporal muscles in patients with temporomandibular myofascial pain and sleep bruxism.

Materials and Methods: The study was conducted based on a clinical record review of 44 patients (36 females and eight males; mean age, $35.70 \pm 12.66$ years). Patients who underwent the injection of botulinum toxin into the masseter and temporal muscles for the management of temporomandibular myofascial pain and sleep bruxism were included in the study. Patients were diagnosed based on the Diagnostic Criteria for Temporomandibular Disorders. Sleep bruxism was diagnosed according to the criteria defined by the American Academy of Sleep Medicine. The values of the visual analogue scale (VAS) and range of jaw motion, including unassisted maximum mouth opening (MMO), protrusion, and right and left laterotrusion, were observed preoperatively and postoperatively at one-, three-, and six-month follow-up visits.

Results: MMO, movements of the right and the left laterotrusion, and protrusion increased significantly $(P<0.05)$, while VAS ratings decreased significantly at the three follow-up points relative to baseline values $(P<0.05)$.

Conclusion: Botulinum toxin is an effective treatment for patients with temporomandibular myofascial pain and sleep bruxism.
\end{abstract}

Key words: Temporomandibular joint disorders, Sleep bruxism, Botulinum toxin

[paper submitted 2020. 3. 3 / revised 2020. 5. 14 / accepted 2020. 5. 19]

\section{Introduction}

Temporomandibular disorders (TMDs) are conditions that affect the temporomandibular joint (TMJ), the chewing muscles, and the other associated structures ${ }^{1}$. Their symptoms include pain in the head, face, neck, and ear; sounds in the TMJ; and restricted jaw movements ${ }^{2}$. TMDs are estimated to affect more than $5 \%$ of the population ${ }^{3}$. The etiology of TMDs is multifactorial, with the most common factors being predisposing factors (e.g., systemic, psychological, structural, and genetic factors), initiating factors (e.g., trauma and parafunctional habits), and perpetuating factors (e.g., mechanical,

\section{Hatice Hosgor}

Department of Oral and Maxillofacial Surgery, Faculty of Dentistry, Kocaeli University, Basiskele, Kocaeli 41190, Turkey

TEL: +90-530-252-46-24 FAX: +90-262-344-21-09

E-mail: drhaticehosgor@yahoo.com

ORCID: https://orcid.org/0000-0002-6925-9526

(c) This is an open-access article distributed under the terms of the Creative Commons Attribution Non-Commercial License (http://creativecommons.org/ licenses/by-nc/4.0/), which permits unrestricted non-commercial use, distribution, and reproduction in any medium, provided the original work is properly cited. Copyright (C) 2020 The Korean Association of Oral and Maxillofacial Surgeons. All rights reserved. muscular stress, and metabolic problems) $)^{4}$.

Bruxism is a well-known risk factor for the development of $\mathrm{TMDs}^{5,6}$. Studies conducted on adults have reported that oral parafunctional habits are a possible cause of TMDs and that parafunctional habits were positively correlated with both muscle disorders and TMDs ${ }^{7-12}$.

Sleep bruxism (SB) is defined as masticatory muscle activity occurring during sleep that is rhythmic (phasic) or nonrhythmic (tonic) and not a movement disorder or a sleep disorder in healthy individuals ${ }^{13}$. SB is a common condition in the general adult population with an estimated prevalence of $5.5 \%$ to $12.8 \% \%^{14,15}$. It can cause various symptoms, such as tooth wear and pain, or malfunction of the chewing system ${ }^{16}$.

Bruxism is most commonly diagnosed using the criteria defined by the American Academy of Sleep Medicine $(\mathrm{AASM})^{17}$, which were last revised in 2014. Accordingly, a patient must meet several criteria to be diagnosed with SB; these include (1) regular or frequent tooth grinding sounds during sleep and (2) one or more of the following clinical signs: (i) abnormal tooth wear or (ii) transient morning jaw muscle pain or fatigue, and/or temporal headache, and/or jaw 
locking on awakening consistent with reports of tooth grinding during sleep.

TMD treatment aims to relieve pain and restore normal temporomandibular functions ${ }^{18}$. Since the pathogenesis of TMDs is not clearly defined, physicians generally prefer noninvasive, reversible, and conservative treatment options and tend to resort to surgery only when conservative treatments are inadequate ${ }^{19}$. The traditional treatment approach for TMDs includes physiotherapy and exercise, antiinflammatory and analgesic drugs, muscle relaxants, oral splints, or a combination of these treatments. Recent studies have reported botulinum toxin (BTX) injections, which has become an increasingly common treatment approach, to be an effective treatment option for relieving pain and sensitivity in $\mathrm{TMDs}^{20,21}$. However, there is currently no definite protocol regarding BTX use in the context of TMDs nor is there a consensus on the effects of BTX in patients with TMDs ${ }^{22}$. The present study sought to evaluate the effect of BTX injection on the pain level and mouth opening capacity when applied to the masseter and temporal muscles of patients with temporomandibular myofascial pain and SB.

\section{Materials and Methods}

This study was approved by the Clinical Research Ethics Committee of Kocaeli University (KÜ GOKAEK 2019/148) and was conducted by way of a clinical records review of 44 patients with temporomandibular myofascial pain and SB admitted to the Department of Oral and Maxillofacial Surgery at Kocaeli University between January 2017 and December 2019.

\section{Patients}

A total of 44 subjects (36 females and eight males) aged between 18 and 73 years were enrolled. Patients who underwent BTX injection into the masseter and temporal muscles were included and subjects in our study were diagnosed using the Diagnostic Criteria for Temporomandibular Disorders ${ }^{23}$, while SB was diagnosed according to the criteria defined by the $\mathrm{AASM}^{17}$. Patient data were obtained via self-reporting and clinical data were recorded.

\section{1) Inclusion criteria}

Patients having 1) resistance to previous conservative treatments (e.g., briefing about the disorder, soft diet, limitations of mouth opening, usage of systemic nonsteroidal anti- inflammatory drugs, and stabilization splint treatment); 2) moderate or severe pain in the masseter and temporal muscle examinations; 3) a diagnosis of SB according to the AASM; and 4) an age of older than 18 years were included.

\section{2) Exclusion criteria}

Patients with 1) the presence of a known connective tissue or autoimmune disease and neuromuscular disease; 2) the concurrent use of steroids, narcotics, or muscle relaxants; 3 ) a known BTX allergy; 4) current pregnancy or lactation; or 5) the presence of infection or skin lesion at the injection site were excluded.

\section{BTX injections}

The patients included in this study underwent a single session of BTX injection in the temporalis and masseter muscles. Immediately before injection, BTX was prepared by dissolving 500 IU of BTX (Dysport; Ipsen, Paris, France) in $2 \mathrm{~mL}$ of room-temperature sterile isotonic saline. A 1-mL syringe with a 26-gauge (13 $\mathrm{mm}$ in length) was used for injections. The patients were asked to clench their jaw to identify and properly inject into the muscle. The solution was injected after careful aspiration; if aspiration indicated intravascular administration, the needle was slightly repositioned and aspiration repeated until the result was negative. A 150-IU solution was administered at three standardized points of the masseter muscles, while a 100-IU solution was administered at two points in the prominent area of the temporalis muscles. The injections were performed in the region where muscle activity was most intense during palpation, along the long axis of the muscle, and at 1-cm intervals apart.

\section{Evaluation of the patients}

Values for the visual analogue scale (VAS) and range of jaw motion - including for maximum mouth opening (MMO), protrusion, and right and left laterotrusion-were observed preoperatively and postoperatively at one-, three-, and six-month follow-up visits.

\section{Statistical analysis}

The IBM SPSS Statistics for Windows (ver. 24.0; IBM, Armonk, NY, USA) was used for statistical analyses. A pairedsamples t-test was adopted for the comparison of parameters with normal distribution and the Wilcoxon signed-test was 
used for the comparison of parameters without normal distribution. The analyses were conducted at a $95 \%$ confidence level. A $P$-value of less than 0.05 was considered to be statistically significant. A multiple regression model was used to identify meaningful associations between the predictors and secondary outcomes.

\section{Results}

A total of 44 patients (36 females and eight males) were evaluated, ranging in age from 18 to 73 years (mean \pm standard deviation age, $35.70 \pm 12.66$ years).

The values for MMO, right and left laterotrusion, protrusion, and VAS at baseline and the first, third, and sixth months of follow-up are presented in Table 1 and Fig. 1. The mean MMO values for all patients were $37.0 \pm 8.88 \mathrm{~mm}$ at baseline, $42.54 \pm 6.98 \mathrm{~mm}$ at the first month, $42.59 \pm 6.90 \mathrm{~mm}$ at the third month, and $42.77 \pm 6.58 \mathrm{~mm}$ at the sixth month. The mean values of the movements of right laterotrusion for all patients were $6.25 \pm 3.05 \mathrm{~mm}$ at baseline, $7.68 \pm 2.37 \mathrm{~mm}$ at the first month, $8.11 \pm 2.37 \mathrm{~mm}$ at the third month, and $8.20 \pm 2.43 \mathrm{~mm}$ at the sixth month, while the mean values of the movements of left laterotrusion for all patients were $7.18 \pm 3.11 \mathrm{~mm}$ at baseline, $8.47 \pm 2.87 \mathrm{~mm}$ at the first month, $8.70 \pm 3.00 \mathrm{~mm}$ at the third month, and $8.56 \pm 3.03 \mathrm{~mm}$ at the sixth month. The mean values of movements of protrusion for all patients were $3.70 \pm 1.93 \mathrm{~mm}$ at baseline, $5.00 \pm 1.84$ $\mathrm{mm}$ at the first month, $5.43 \pm 2.12 \mathrm{~mm}$ at the third month, and $5.38 \pm 1.99 \mathrm{~mm}$ at the sixth month. Finally, the mean VAS values for all patients were $7.09 \pm 1.77$ at baseline, $2.90 \pm 2.89$ at the first month, $1.95 \pm 2.26$ at the third month, and $2.11 \pm 2.19$ at the sixth month.

The evaluation of all data showed that MMO, movements of the right and the left laterotrusion, and protrusion increased significantly with BTX treatment $(P<0.05)$, while VAS values decreased significantly progressively during follow-up relative to the baseline values $(P<0.05)$. Moreover, the pain level was decreased by $59 \%$ in the first month, $72 \%$ in the third month, and $70 \%$ in the sixth month after treatment initiation. MMO, movements of the right and the left laterotrusion, protrusion, and VAS values at the sixth month did not differ by patient age $(P>0.05)$.

\section{Discussion}

Parafunctions such as bruxism may damage TMJ tissues due to the disproportionate and repetitive excessive load on the $\mathrm{TMJ}^{24,25}$. Bruxism can result in clinical symptoms such as headache and TMJ together with chewing muscle pain and hypertrophy ${ }^{26,27}$. In addition, bruxism is considered to be a risk factor for the development of TMD signs and symptoms ${ }^{28}$.

Experimental studies have shown increased interstitial pressure and the development of intramuscular edema due to bruxism. Muscle pain is an expected consequence of intramuscular edema ${ }^{29}$. In this study, all patients with SB experienced pain in the masticatory muscles when awakened and there were also signs of pain during muscle examinations.

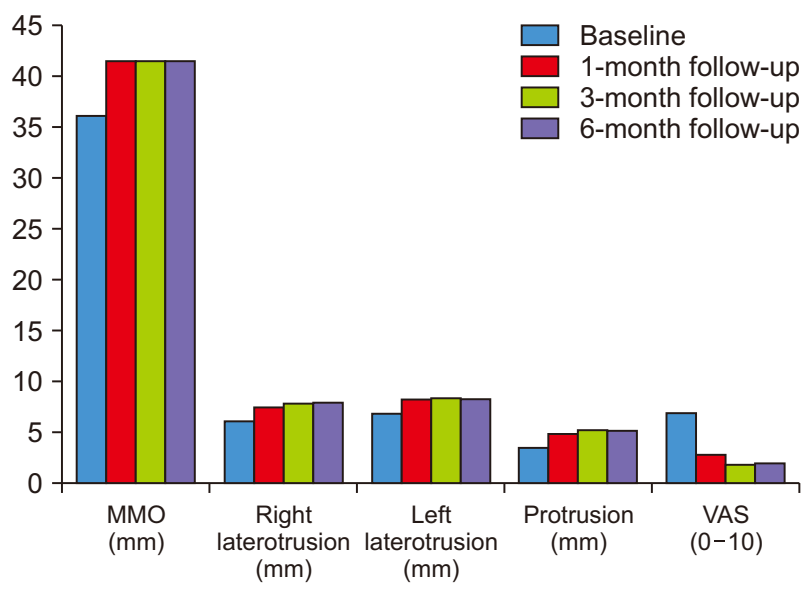

Fig. 1. The distribution of maximum mouth opening (MMO), right laterotrusion, left laterotrusion, protrusion, and visual analogue scale (VAS) scores at baseline, 1st-month, 3rd-month, and 6thmonth.

Hatice Hosgor et al: Efficacy of botulinum toxin in the management of temporomandibular myofascial pain and sleep bruxism. J Korean Assoc Oral Maxillofac Surg 2020

Table 1. The values of maximum mouth opening (MMO), right laterotrusion, left laterotrusion, protrusion, and visual analogue scale (VAS) at baseline and the first, third, and sixth months of follow-up

\begin{tabular}{lccrc}
\hline \multicolumn{1}{c}{ Outcome measure } & Baseline & 1-month follow-up & 3-month follow-up & 6-month follow-up \\
\hline MMO (mm) & $37.0 \pm 8.88$ & $42.54 \pm 6.98$ & $42.59 \pm 6.90$ & $42.77 \pm 6.58$ \\
Right laterotrusion $(\mathrm{mm})$ & $6.25 \pm 3.05$ & $7.68 \pm 2.37$ & $8.11 \pm 2.37$ & $8.20 \pm 2.43$ \\
Left laterotrusion $(\mathrm{mm})$ & $7.18 \pm 3.11$ & $8.47 \pm 2.87$ & $8.70 \pm 3.00$ & $8.56 \pm 3.03$ \\
Protrusion $(\mathrm{mm})$ & $3.70 \pm 1.93$ & $5.00 \pm 1.84$ & $5.43 \pm 2.12$ & $5.38 \pm 1.99$ \\
VAS (0-10) & $7.09 \pm 1.77$ & $2.90 \pm 2.89$ & $1.95 \pm 2.26$ & $2.11 \pm 2.19$ \\
\hline
\end{tabular}

Hatice Hosgor et al: Efficacy of botulinum toxin in the management of temporomandibular myofascial pain and sleep bruxism. J Korean Assoc Oral Maxillofac Surg 2020 
TMD and myofascial pain treatments primarily involve conservative approaches and symptomatic therapies ${ }^{30}$ and the destructive effect of bruxism on anatomical structures should be limited ${ }^{27,31}$.

Recent studies have investigated the effects of BTX injections on TMD, bruxism, masseter hypertrophy, and myofascial pain ${ }^{26,27,32-34}$. BTX facilitates muscle relaxation by temporarily blocking the release of $\mathrm{Ca}^{+2}$-mediated acetylcholine from the myoneural junction. When synaptic regeneration occurs, the neuromuscular transfer resumes and paralysis subsides $^{35}$. This process of relief with BTX therapy enables the patient to resolve the cause of the complaint ${ }^{36}$.

In a randomized controlled study ${ }^{37}$, BTX was injected in the masseter and temporal muscles in patients with nocturnal bruxism $(\mathrm{n}=6)$, while a saline solution was injected in patients in the control group $(\mathrm{n}=6)$. The follow-up controls in the fourth, eighth, and 12th weeks showed that bruxism activity decreased significantly in the treatment group. However, there was still bruxism-related pain in the temporal muscles. Likewise, in the study conducted by Guarda-Nardini et al. ${ }^{38}$, BTX was injected in the chewing muscles in patients with bruxism and myofascial pain $(\mathrm{n}=10)$, while a saline solution was injected in the chewing muscles in the control group $(\mathrm{n}=10)$. Patients were evaluated for MMO, lateral-protrusive movements, and pain, with results suggesting that pain was relieved and that subjective clinical symptoms were improved significantly in the BTX group relative to in the placebo group. These authors concluded that BTX was an effective treatment in patients with bruxism and myofascial pain syndrome. Meanwhile, Al-Wayli ${ }^{32}$ evaluated the treatment of nocturnal bruxism-related pain in 25 patients injected with BTX and 25 patients managed with conventional methods. The study patients were examined after three weeks and in the second and sixth months after treatment, then evaluated later on at the end of the first year. Study results indicated that pain was relieved significantly in the BTX group, while the degree of pain reduction in the conventional treatment group was unremarkable. Finally, comparing the efficacy of BTX with that of saline solution in achieving pain reduction among 20 patients with bruxism and myofascial pain in the masticatory muscles, Guarda-Nardini et al..$^{39}$ observed significant improvement in jaw movements, including regarding mouth opening, after BTX injection.

In our study, we observed a significant improvement in jaw movements at the first, third, and sixth months after BTX injection, together with a decrease in the pain level. It is known that local paralysis occurring in the muscle after BTX injec- tion reoccurs after two to four months ${ }^{40}$. Although the physiological efficacy of BTX decreased, the reason behind why symptoms continued to decline may be due to patients being more aware of parafunctional habits and working toward having more controlled functional habits, while may have allowed other muscles involved in the chewing function to function normally.

There are studies that have examined different doses and injection techniques of BTX to eliminate the imbalance in the chewing muscles and reduce pain. Ernberg et al. ${ }^{40}$ performed injections after dissolving $100 \mathrm{IU}$ of freeze-dried BTX (Botox; Allergan, Dublin, Ireland) into $1.0 \mathrm{~mL}$ of room-temperature sterile isotonic saline and applied 50 IU BTX to each muscle. Guarda-Nardini et al. ${ }^{39}$ injected 150 IU of BTX (Dysport) on each treated side with a five-point injection minimum, employing a reverse pyramid pattern in the masseter muscles and a chess-board pattern for the temporalis muscles. Kim et al. ${ }^{41}$ injected a total of $500 \mathrm{IU}$ of BTX (Dysport) injections in the bilateral masseter and temporalis muscles at a 3:2 ratio. In our practice, similar to in the study of Kim et al. ${ }^{41}$, we used a total of 250 IU of BTX (Dysport) for injection into each side. Therefore, clarity regarding the optimal application dosage remains to be attained.

Ernberg et al. ${ }^{40}$ reported that a significant pain-reducing effect $(30 \%)$ was found after BTX injections at the first month of follow-up. In the study by Guarda-Nardini et al. ${ }^{39}$ comparing BTX and saline solution injections, a 50\% pain reduction at one month after BTX injections was reported, while Kurtoglu et al. ${ }^{42}$ observed a $22 \%$ pain reduction at one month of follow-up. In our study, the pain level was decreased by $59 \%$ in the first postoperative month, $72 \%$ in the third month, and $70 \%$ in the sixth month.

It has been reported that, after BTX injection, complications such as chewing difficulties, muscle pain, speech disorder, and abnormal changes in facial appearance can occur. Such complications are reported to be transient nature, lasting one to four weeks ${ }^{43}$. There is also a low probability of allergic skin reactions or immunological responses ${ }^{44}$, but we did not observe these outcomes in our patients.

Research cautions that there are no current standards for postevaluation and follow-up protocols relating to the administration of BTX injection ${ }^{45}$. In our study, it was observed that patients experienced a significant increase in mouth opening and decreased pain levels even in the postoperative sixth month. Therefore, it is important to monitor how long BTX activity is effective in treated patients. We suggest that pursuing regular follow-up examinations is essential to accurately 
determine the need for BTX re-treatment.

\section{Conclusion}

Bruxism is defined as repetitive jaw muscle activity characterized by the clenching or grinding of teeth and is known to cause TMD and myofascial pain. TMD treatment aims to eliminate the causative factor of this condition. Our study suggests BTX is effective in the symptomatic treatment for patients with temporomandibular myofascial pain and SB. However, studies involving larger groups and long period follow-ups should be conducted.

\section{ORCID}

Hatice Hosgor, https://orcid.org/0000-0002-6925-9526

Sezen Altindis, https://orcid.org/0000-0001-9649-4356

\section{Authors' Contributions}

H.H. and S.A. participated in data collection and H.H. wrote the manuscript. H.H. and S.A. have read and approved the final manuscript.

\section{Ethics Approval and Consent to Participate}

The study was approved by the Clinical Research Ethics Committee of Kocaeli University (KÜ GOKAEK 2019/148), and written informed consent was obtained from all patients.

\section{Conflict of Interest}

No potential conflict of interest relevant to this article was reported.

\section{References}

1. Lora VR, Canales Gde L, Gonçalves LM, Meloto CB, Barbosa $\mathrm{CM}$. Prevalence of temporomandibular disorders in postmenopausal women and relationship with pain and HRT. Braz Oral Res 2016;30:e100. https://doi.org/10.1590/1807-3107BOR-2016. vol30.0100

2. Nayyar P, Kumar P, Nayyar PV, Singh A. Botox: broadening the horizon of dentistry. J Clin Diagn Res 2014;8:ZE25-9. https://doi. org/10.7860/JCDR/2014/11624.5341

3. Miloro M, Ghali GE, Larsen P, Waite P. Peterson's principles of oral and maxillofacial surgery. 3rd ed. Shelton: People's Medical Publishing House; 2012.

4. Maini K, Dua A. Temporomandibular joint syndrome [Internet]. Treasure Island (FL): StatPearls Publishing [cited 2020 May 10].
Available from: https://www.ncbi.nlm.nih.gov/books/NBK551612/.

5. Koyano K, Tsukiyama Y, Ichiki R, Kuwata T. Assessment of bruxism in the clinic. J Oral Rehabil 2008;35:495-508. https://doi. org $/ 10.1111 / j .1365-2842.2008 .01880 . x$

6. Jiménez-Silva A, Peña-Durán C, Tobar-Reyes J, Frugone-Zambra $\mathrm{R}$. Sleep and awake bruxism in adults and its relationship with temporomandibular disorders: a systematic review from 2003 to 2014 . Acta Odontol Scand 2017;75:36-58. https://doi.org/10.1080/00016 357.2016.1247465

7. Macfarlane TV, Gray RJM, Kincey J, Worthington HV. Factors associated with the temporomandibular disorder, pain dysfunction syndrome (PDS): Manchester case-control study. Oral Dis 2001;7:321-30. https://doi.org/10.1034/j.1601-0825.2001.00758.x

8. Glaros AG, Burton E. Parafunctional clenching, pain, and effort in temporomandibular disorders. J Behav Med 2004;27:91-100. https://doi.org/10.1023/b:jobm.0000013646.04624.8f

9. van der Meulen MJ, Lobbezoo F, Aartman IH, Naeije M. Self-reported oral parafunctions and pain intensity in temporomandibular disorder patients. J Orofac Pain 2006;20:31-5.

10. Magnusson T, Egermarki I, Carlsson GE. A prospective investigation over two decades on signs and symptoms of temporomandibular disorders and associated variables. A final summary. Acta Odontol Scand 2005;63:99-109. https://doi. org/10.1080/00016350510019739

11. Ciancaglini R, Gherlone EF, Radaelli G. The relationship of bruxism with craniofacial pain and symptoms from the masticatory system in the adult population. J Oral Rehabil 2001;28:842-8. https:// doi.org/10.1046/j.1365-2842.2001.00753.x

12. Uchida M, Yatani H, Ishigaki S, Toda M, Morimoto K. Relations among TMD, bruxism, lifestyle, and psychological stress. Prosthodont Res Pract 2008;7:171-3.

13. Lobbezoo F, Ahlberg J, Raphael KG, Wetselaar P, Glaros AG, Kato $\mathrm{T}$, et al. International consensus on the assessment of bruxism: report of a work in progress. J Oral Rehabil 2018;45:837-44. https:// doi.org/10.1111/joor.12663

14. Manfredini D, Winocur E, Guarda-Nardini L, Paesani D, Lobbezoo F. Epidemiology of bruxism in adults: a systematic review of the literature. J Orofac Pain 2013;27:99-110. https://doi.org/10.11607/ jop. 921

15. Maluly M, Andersen ML, Dal-Fabbro C, Garbuio S, Bittencourt L, de Siqueira JT, et al. Polysomnographic study of the prevalence of sleep bruxism in a population sample. J Dent Res 2013;92(7 Suppl):97S-103S. https://doi.org/10.1177/0022034513484328

16. Ohayon MM, Li KK, Guilleminault C. Risk factors for sleep bruxism in the general population. Chest 2001;119:53-61. https://doi. org/10.1378/chest.119.1.53

17. American Academy of Sleep Medicine. International classification of sleep disorders. 3rd ed. Darien (IL): American Academy of Sleep Medicine; 2014:303-11.

18. Suvinen TI, Reade PC, Hanes KR, Könönen M, Kemppainen P. Temporomandibular disorder subtypes according to self-reported physical and psychosocial variables in female patients: a reevaluation. J Oral Rehabil 2005;32:166-73. https://doi.org/10.1111/ j.1365-2842.2004.01432.x

19. List T, Axelsson S. Management of TMD: evidence from systematic reviews and meta-analyses. J Oral Rehabil 2010;37:430-51. https://doi.org/10.1111/j.1365-2842.2010.02089.x

20. Freund B, Schwartz M, Symington JM. The use of botulinum toxin for the treatment of temporomandibular disorders: preliminary findings. J Oral Maxillofac Surg 1999;57:916-20; discussion 9201. https://doi.org/10.1016/s0278-2391(99)90007-1

21. Lee KM, Chow J, Hui E, Li W. Botulinum toxin type A injection for the management of myofascial temporomandibular pain disorder. Asian J Oral Maxillofac Surg 2005;17:100-3. https://doi. org/10.1016/S0915-6992(05)80032-9

22. De la Torre Canales G, Câmara-Souza MB, do Amaral CF, Garcia $\mathrm{RC}$, Manfredini D. Is there enough evidence to use botulinum toxin 
injections for bruxism management? A systematic literature review. Clin Oral Investig 2017;21:727-34. https://doi.org/10.1007/s00784017-2092-4

23. Schiffman E, Ohrbach R, Truelove E, Look J, Anderson G, Goulet JP, et al.; International RDC/TMD Consortium Network, International association for Dental Research; Orofacial Pain Special Interest Group, International Association for the Study of Pain. Diagnostic criteria for temporomandibular disorders (DC/TMD) for clinical and research applications: recommendations of the International RDC/TMD Consortium Network* and Orofacial Pain Special Interest Group ${ }^{\dagger}$ J Oral Facial Pain Headache 2014;28:6-27. https://doi.org/10.11607/jop.1151

24. Nitzan DW. Intraarticular pressure in the functioning human temporomandibular joint and its alteration by uniform elevation of the occlusal plane. J Oral Maxillofac Surg 1994;52:671-9; discussion 679-80. https://doi.org/10.1016/0278-2391(94)90476-6

25. Sharav Y, Benoliel R. Orofacial pain \& headache. Edinburgh: Mosby; 2008:161.

26. Güleç M, Taşsöker M, Özcan S. [Bruksizmin tanı ve tedavisinde güncel yaklaşımlar]. Selcuk Dent J 2019;6:221-8. Turkish.

27. Tinastepe N, Küçük BB, Oral K. Botulinum toxin for the treatment of bruxism. Cranio 2015;33:291-8. https://doi.org/10.1080/088696 34.2015 .1097296

28. Manfredini D, Lobbezoo F. Relationship between bruxism and temporomandibular disorders: a systematic review of literature from 1998 to 2008. Oral Surg Oral Med Oral Pathol Oral Radiol Endod 2010;109:e26-50. https://doi.org/10.1016/j.tripleo.2010.02.013

29. Ariji Y, Sakuma S, Izumi M, Sasaki J, Kurita K, Ogi N, et al. Ultrasonographic features of the masseter muscle in female patients with temporomandibular disorder associated with myofascial pain. Oral Surg Oral Med Oral Pathol Oral Radiol Endod 2004;98:33741. https://doi.org/10.1016/j.tripleo.2004.06.068

30. Abouelhuda AM, Khalifa AK, Kim YK, Hegazy SA. Non-invasive different modalities of treatment for temporomandibular disorders: review of literature. J Korean Assoc Oral Maxillofac Surg 2018;44:43-51. https://doi.org/10.5125/jkaoms.2018.44.2.43

31. Fernández-Núñez T, Amghar-Maach S, Gay-Escoda C. Efficacy of botulinum toxin in the treatment of bruxism: systematic review. Med Oral Patol Oral Cir Bucal 2019;24:e416-24. https://doi. org/10.4317/medoral.22923

32. Al-Wayli H. Treatment of chronic pain associated with nocturnal bruxism with botulinum toxin. A prospective and randomized clinical study. J Clin Exp Dent 2017;9:e112-7. https://doi.org/10.4317/ jced.53084

33. Sidebottom AJ, Patel AA, Amin J. Botulinum injection for the management of myofascial pain in the masticatory muscles. A prospective outcome study. Br J Oral Maxillofac Surg 2013;51:199205. https://doi.org/10.1016/j.bjoms.2012.07.002

34. Ahn J, Horn C, Blitzer A. Botulinum toxin for masseter reduction in Asian patients. Arch Facial Plast Surg 2004;6:188-91. https://doi. org/10.1001/archfaci.6.3.188

35. Majid OW. Clinical use of botulinum toxins in oral and maxillofa- cial surgery. Int J Oral Maxillofac Surg 2010;39:197-207. https:// doi.org/10.1016/j.ijom.2009.10.022

36. Dressler D, Saberi FA, Barbosa ER. Botulinum toxin: mechanisms of action. Arq Neuropsiquiatr 2005;63:180-5. https://doi. org/10.1590/s0004-282x2005000100035

37. Lee SJ, McCall WD Jr, Kim YK, Chung SC, Chung JW. Effect of botulinum toxin injection on nocturnal bruxism: a randomized controlled trial. Am J Phys Med Rehabil 2010;89:16-23. https://doi. org/10.1097/PHM.0b013e3181bc0c78

38. Guarda-Nardini L, Manfredini D, Salamone M, Salmaso L, Tonello S, Ferronato G. Efficacy of botulinum toxin in treating myofascial pain in bruxers: a controlled placebo pilot study. Cranio 2008;26:126-35. https://doi.org/10.1179/crn.2008.017

39. Guarda-Nardini L, Stecco A, Stecco C, Masiero S, Manfredini D. Myofascial pain of the jaw muscles: comparison of short-term effectiveness of botulinum toxin injections and fascial manipulation technique. Cranio 2012;30:95-102. https://doi.org/10.1179/ crn.2012.014

40. Ernberg M, Hedenberg-Magnusson B, List T, Svensson P. Efficacy of botulinum toxin type A for treatment of persistent myofascial TMD pain: a randomized, controlled, double-blind multicenter study. Pain 2011;152:1988-96. https://doi.org/10.1016/ j.pain.2011.03.036

41. Kim HS, Yun PY, Kim YK. A clinical evaluation of botulinum toxin-A injections in the temporomandibular disorder treatment. Maxillofac Plast Reconstr Surg 2016;38:5. https://doi.org/10.1186/ s40902-016-0051-7

42. Kurtoglu C, Gur OH, Kurkcu M, Sertdemir Y, Guler-Uysal F, Uysal H. Effect of botulinum toxin-A in myofascial pain patients with or without functional disc displacement. J Oral Maxillofac Surg 2008;66:1644-51. https://doi.org/10.1016/j.joms.2008.03.008

43. Klein FH, Brenner FM, Sato MS, Robert FM, Helmer KA. Lower facial remodeling with botulinum toxin type A for the treatment of masseter hypertrophy. An Bras Dermatol 2014;89:878-84. https:// doi.org/10.1590/abd1806-4841.20143200

44. Borodic G. Botulinum toxin, immunologic considerations with long-term repeated use, with emphasis on cosmetic applications. Facial Plast Surg Clin North Am 2007;15:11-6, v. https://doi. org/10.1016/j.fsc.2006.10.001

45. Chen YW, Chiu YW, Chen CY, Chuang SK. Botulinum toxin therapy for temporomandibular joint disorders: a systematic review of randomized controlled trials. Int J Oral Maxillofac Surg 2015;44:1018-26. https://doi.org/10.1016/j.ijom.2015.04.003

How to cite this article: Hosgor H, Altindis S. Efficacy of botulinum toxin in the management of temporomandibular myofascial pain and sleep bruxism. J Korean Assoc Oral Maxillofac Surg 2020;46:335-340. https://doi.org/10.5125/jkaoms.2020.46.5.335 